\title{
Identificação pela provisão: uma estratégia para a identificação das Altas Habilidades/Superdotação em adultos?
}

Nara Joyce Wellausen Vieira*

\section{Resumo}

Este estudo objetivou a identificação dos indicadores de altas habilidades/superdotação nos acadêmicos participantes do Programa de Educação Tutorial (PET) na UFSM. A seleção desta população como populaçáo-alvo da pesquisa se justifica pela proximidade dos objetivos do Programa de Educação Tutorial e do Programa de Enriquecimento Curricular, proposta de atendimento educacional oferecida aos estes alunos na educação básica. Os principais autores que subsidiaram o estudo foram Joseph Renzulli, Howard Gardner, Susana Pérez e Soraia Freitas. A metodologia utilizada fundamentou-se na abordagem qualitativa utilizando como procedimentos de coleta de dados a provisão de situaçóes desafiantes, aplicação de instrumentos padronizados, grupos focais e entrevista individual. A intervenção foi realizada em dois grupos PETs e foram encontrados seis acadêmicas e dois acadêmicos com indicadores de altas habilidades/superdotação. Os resultados apontaram a possibilidade de se usar a identificação pela provisáo como um procedimento válido no processo de identificação da pessoa com altas habilidades/superdotação, além de indicar o PET como um recurso importante para a inclusão destes acadêmicos que, pelo apoio dos colegas e da tutora, se sentem reconhecidos e fortificados em sua autoestima. Ao mesmo tempo, foi possível observar que todos os alunos que participam dos grupos PETs observados estão satisfeitos com sua escolha profissional e com sua ação como profissionais nas comunidades, são alegres, participativos e espontâneos, o que desperta em quem entra um grande desejo de trabalhar com/neste estes grupos.

Palavras-chave: Educação Especial; Inclusão no Ensino Superior; Identificação das Altas Habilidades/Superdotação; Programa de Educação Tutorial.

* Professora Doutora da Universidade Federal de Santa Maria (UFSM). Santa Maria, Rio Grande do Sul, Brasil. 


\section{Identification Through Provision: High Ability/ Giftedness Identification Strategy in Grown-ups?}

\section{Abstract}

This research aimed at the identification of high ability/giftedness indicators in the students who take part of the Tutorial Educational Program (PET) at the Federal University of Santa Maria (UFSM). The choice of this population as research target is justified because the Tutorial Educational Program objectives are similar to those of the Curriculum Enrichment Program, educational service proposal offered to these students in elementary and secondary schools. The main authors supporting the study were Joseph Renzulli, Howard Gardner, Susana Pérez and Soraia Freitas. The qualitative research methodology has used provision of challenging situations, standardized identification instruments, focal groups and individual interviews as data collecting procedures. The intervention was performed in two PET groups, along with six female and two male students in which high ability/giftedness indicators were found. Results have shown the possibility of using identification through provision as a valid procedure in the identification process of people with high ability/ giftedness, also indicating PET as an important resource to include these students, who, by the support of their colleagues and tutor, feel recognized and have their self-esteem strengthened. At the same time, it was possible to note that all the students participating of the observed PET groups are satisfied with their professional choice and their professional action in the communities; they are cheerful, participative and spontaneous, encouraging newcomers to work with/in these groups.

Keywords: Special Education; Inclusion in Higher Education; High ability/giftedness identification; Tutorial Educational Program.

\section{Iniciando a discussão...}

As pessoas com altas habilidades/superdotação (AH/SD) fazem parte da populaçáo atendida pela Educação Especial e estáo regularmente matriculados nos sistemas de ensino. No entanto, pela condição de apresentar habilidades superiores em algumas áreas em relação à média da população, é comum não haver uma preocupação maior com o atendimento a estes sujeitos, no Brasil. Como observam Freitas e Pérez (2010, 2012), em relação ao adulto com AH/SD esta situação é mais grave ainda, pois é possível afirmar que poucos são os programas de atendimento dirigidos a este grupo social no Ensino Superior. E, menos ainda são os estudos e pesquisas nesta modalidade de ensino e com esta faixa etária. Pela pesquisa na internet, encontramos dois artigos, uma dissertação de Mestrado e uma de Doutorado envolvendo a temática.

Na Universidade Federal de Santa Maria (UFSM), desde 2007, temos um Núcleo destinado a pensar e propor apoio aos acadêmicos oriundos da Educaçáo 
Especial - alunos com deficiências, transtornos globais do desenvolvimento e altas habilidades/superdotação. Algumas ações são planejadas e articuladas para estes dois primeiros grupos e hoje é possível afirmar que a universidade tem $152^{1}$ alunos regulares com deficiências matriculados em seus campos. Porém, onde estáo os alunos com altas habilidades/superdotação? Pelas estimativas da Organização Mundial da Saúde, 3\% a 5\% de qualquer população apresentam indicadores de altas habilidades/ superdotação. Na UFSM temos, hoje, $29.477^{2}$ alunos. Considerando a prevalência, teríamos 884 a 1.474 alunos com AH/SD na universidade. Não é importante identificar e propor uma intervenção para estes acadêmicos?

Neste sentido, este artigo pretende relatar a execução do projeto de pesquisa intitulado Identificação dos Indicadores de Altas Habilidades/Superdotação em Acadêmicos da UFSM, que tem como objetivo identificar os comportamentos indicativos de AH/SD nos alunos que frequentam um programa de educação que promove e potencializa as habilidades e interesses destacados destes acadêmicos na busca de otimizar sua formação profissional e pessoal - o Programa de Educação Tutorial (PET).

Muitas são as semelhanças entre o PET e o enriquecimento curricular proposto por Renzulli $(2004,2001,1986)$. O enriquecimento se constitui como um dos modelos que o atendimento educacional especializado pode oferecer aos alunos com AH/SD na educação básica; e a semelhança entre as duas propostas é que ambas visam enaltecer o potencial e/ou habilidades através de atividades extracurriculares dos discentes em questão.

No PET, há um professor responsável pelas açôes que serão feitas pelos alunos, porém é responsabilidade do discente "formular novas estratégias de desenvolvimento e modernização do ensino superior no país" buscando estimular através destas estratégias a melhoria do ensino de graduação. É objetivo do PET "oferecer uma formação acadêmica de excelente nível, visando à formação de um profissional crítico e atuante, orientada pela cidadania e ela função social na educação superior" (BRASIL, 2006, p. 7-8)

Portanto, considera-se justificada a proposta de um estudo desta natureza como forma de investigar quem são e onde estấo estes indivíduos e quais são suas necessidades no ensino superior. Da mesma forma esta proposta está em consonância com os objetivos da universidade, pois pode transformar-se como campo para o ensino e a extensão aos alunos do Curso de Licenciatura em Educação Especial, que inclui em seu currículo, no sexto e sétimo semestres, disciplinas que envolvem a temática das AH/SD. Neste sentido, desde o inicio do projeto, três alunas do curso estấo acompanhando as atividades, sendo que uma delas foi bolsista PROLICEN e as outras duas eram estagiárias do Núcleo de Acessibilidade da UFSM.

\section{que se fala na literatura...}

Em qualquer programa de atendimento às AH/SD a identificação é, sem dúvida, um dos fatores mais importantes a se considerar. Alguns dos procedimentos utilizados, usualmente para o reconhecimento destas pessoas, porém, não contemplam a totalidade das suas potencialidades (VIEIRA, 2002). Por um lado, os testes 
de inteligência verificam áreas valorizadas pelo sistema acadêmico, e, por outro, não investigam áreas como o destaque no uso do corpo, a criatividade, as expressóes artísticas, musicais, dentre outras. Tampouco, o reconhecimento feito através do preenchimento de listas de indicadores, pelos pais, professores e colegas, contempla a totalidade das áreas. Por serem listas que apresentam características, comportamentos e traços atribuídos aos sujeitos com AH/SD, variam consideravelmente de acordo com os valores socioculturais, além de sofrerem interferência dos valores afetivos e do grau de relação existente entre o avaliador e o sujeito avaliado. Pesquisadores como Renzulli et al (2001), Freeman e Guenther (2000), Gardner, Feldman e Krechevsky (2001) são unânimes em afirmar que a identificação deve ser feita através de um conjunto de procedimentos, que possibilitem uma visão integral deste sujeito. Estes autores também valorizam a ideia da utilização de múltiplos critérios, considerando-se informaçóes obtidas de diferentes fontes. Neste sentido, pode-se observar, na literatura, processos de identificação que contemplam tanto a autoinformação ou o autorreconhecimento dos alunos, quanto à contribuiçáo de seus familiares, amigos e professores (VIEIRA, 2005a).

Defendemos a posição de que é possível estabelecer procedimentos que valorizem tanto as áreas do saber quanto aquelas que abrangem o fazer e o sentir. Entendemos que tal proposta não se constitui numa atividade simplificadora, mas, sim, em açóes que consideram o ambiente natural desses sujeitos, podendo ser utilizada com todo o público-alvo da educação especial, uma vez que retira o foco da visão clínicomédica embutida no "diagnóstico" e centra o olhar na atividade do sujeito sistêmico, com limitaçôes e potencialidades. Este procedimento é nomeado de identificação pela provisão e é definido por Freeman e Guenther (2000) como o oferecimento de experiências que estimulam e desafiam as pessoas com AH/SD. Os papéis do mediador nessa atividade sáo, numa ação intencional anterior ao oferecimento das experiências, organizar o espaço físico, selecionar o material a ser utilizado pelas crianças/ adolescentes/adultos e, durante a atividade propriamente dita, combinar as regras que regerão o trabalho, facilitar e promover a interação com os materiais oferecidos e entre os sujeitos. A identificação pela provisão, portanto, não trata de formatar "provas" para a criança/adolescente/adulto responder, mas, sim, de estimulá-los para a ação, através de tarefas e materiais que lhe desafiem e despertem o interesse. Entretanto, numa proposta de identificaçáo dessa natureza, fica como desafio a promoção do envolvimento de profissionais de áreas diferenciada tais como música, esportes e artes, dentre outras.

Cabe agora apresentar as duas concepçôes que subsidiam este trabalho: inteligência (GARDNER, 2000) e altas habilidades/superdotação (RENZULLI, 1986, 2004). A pessoa com AH/SD tem sido definida como mais inteligente em relação à média. Desta forma, os estudos nessa área estão intimamente ligados aos da inteligência (VIEIRA, 2005b). Plucker (2001) destaca que a inter-relação entre estes dois conceitos é bastante forte e influencia tanto a maneira de identificar e educar os alunos com $\mathrm{AH} / \mathrm{SD}$, quanto as nossas atitudes em relação a eles. 
Nesta perspectiva, a concepção modular de inteligência proposta por Gardner (2000) pode ser entendida como uma proposta diferenciada para o entendimento da cognição humana. Para o autor a inteligência não pertence a um grupo específico de estudiosos, mas, desde um olhar multidisciplinar, abrange muitas áreas de interesse que participarão de seu estudo. Inteligência é definida como "um potencial biopsicológico para processar informaçóes que pode ser ativado num cenário cultural para solucionar problemas ou criar produtos que sejam valorizados numa cultura" (GARDNER, 2000, p. 47).

Essa concepção diferenciada de inteligência possibilita um reconhecimento das diferentes formas e estilos contrastantes que as pessoas têm/usam para conhecer as coisas ao seu redor e a si mesmas. Assim sendo, as inteligências acontecem simultaneamente, pois uma ação exige vários tipos de inteligências. Portanto, elas se inter-relacionam e se complementam entre si. Até o momento são oito, as inteligências, caracterizadas pelo autor, e assim nomeadas: linguística, lógico-matemática, espacial, corporal-cinestésica, naturalista, musical, intrapessoal e interpessoal. Não é nossa intenção analisar cada uma destas inteligências neste momento, mas o que é importante salientar é que esta é uma nova contribuição para o debate sobre os potenciais cognitivos e, muito provavelmente, a abordagem de identificação ancorada nos princípios das Inteligências Múltiplas aponte muito mais pessoas com altas habilidades/superdotação, uma vez que considera uma ampla gama de habilidades e não somente aquelas competências tradicionalmente avaliadas pelos testes psicométricos (VIEIRA, 2005b).

No que se refere à concepção de AH/SD, Renzulli $(1986,2004)$ elaborou a teoria dos Três Anéis da Superdotaçáo, representada graficamente por um diagrama de Venn. Cada anel constitui um traço existente no sujeito. São eles: habilidade acima da média, comprometimento com a tarefa e criatividade. A intersecção destes três fatores compóe a superdotação. Os três anéis estão amparados por uma rede significando o contexto social em que o sujeito vive e os fatores intrínsecos ao próprio sujeito, os quais oferecem condiçôes para que os três traços se manifestem. Esta visão sistêmica apresentada pelo autor valoriza o pensamento contextual e processual, a partir do qual os sistemas vivos são percebidos como totalidades integradas, resultantes não da soma das partes, mas da relação de organização das partes. Nesta concepção, nenhuma das partes é mais importante do que a outra. É exatamente a organização deste sistema que determina a interação entre elas e a estruturação do todo. Em outras palavras, "não se considera o indivíduo superdotado pela soma de uma série de qualidades que ele apresenta em seu comportamento, mas sim pela forma sistêmica como estas qualidades interagem entre si e com seu ambiente" (VIEIRA, 2005a, p.66).

Como estas características se manifestam na pessoa com altas habilidades adulta? Muitos são os estudos relacionados à criança e ao adolescente com estas características. Porém, como já foi mencionado anteriormente, poucos pesquisadores enfocaram o superdotado ${ }^{3}$ adulto (PEREZ, 2008; DELPRETTO, 2009, 2010; MOSQUERA, STOBÄUS e FREITAS, 2013). 
Segundo Pérez (2008), as pessoas com altas habilidades/superdotação adul-

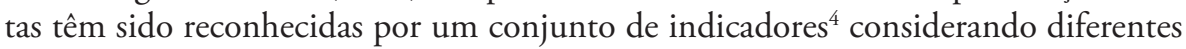
áreas do conhecimento, sendo os mais frequentes: busca de soluçôes próprias para os problemas; capacidade desenvolvida de análise, avaliação e julgamento; independência de pensamento; grande produção de ideias; concentração prolongada numa atividade de interesse; consciência de si mesmo e de suas diferenças; desgosto com a rotina; gosto pelo desafio; habilidade em áreas específicas; interesse por assuntos e temas complexos e persistência perante dificuldades inesperadas (PÉREZ, 2008).

Evidenciamos que as AH/SD se constituem em um estado peculiar do desenvolvimento humano entendendo que o desenvolvimento náo acontece somente pela maturação biológica, mas, também, pela ontológica que evidencia a natureza inerente a todos e a cada um dos seres humanos. Neste sentido, buscamos amparo nas palavras de Mosquera, Stobäus e Freitas (2013, p. 404) que afirmam:

Na vida adulta, pessoas intelectualmente superdotadas também dispóem de capacidades, potencialidades e recursos que facilitam sua adaptação ao meio. Porém, devemos levar em conta a importância das relaçóes com o entorno, no qual as pessoas se desenvolvem, favorecendo (ou não) seu desenvolvimento global. Gostaríamos de chamar atenção para a idéia de que existiriam dois tipos de adultos com altas habilidades/superdotação: os superdotados adaptados e os não-adaptados.

A contribuição dos autores evidencia e justifica a preocupação para a necessidade de uma educação que respeite as singularidades das pessoas com AH/SD desde muito cedo e ao longo de sua vida, para que possam desfrutar de seus potenciais como coisas positivas e que lhes permitam um melhor aproveitamento e satisfação pessoal.

No entanto, quais são os procedimentos mais adequados para reconhecer estes sujeitos na vida adulta?

Muitas são as dúvidas em um processo de identificação que adota o modelo de provisão de tarefas desafiadoras. A identificação pela provisão considerando os indicadores é correta? Tradicionalmente, embora se fale em múltiplos instrumentos, os resultados obtidos nos testes de inteligência são decisivos para a identificação de quem é superdotado ou não. Ficamos pensando, entretanto, nos outros indivíduos, aqueles que se destacam na música, no desenho, no teatro, na dança, como identificá-los? Como ajudar a todos a se desenvolverem, respeitando a singularidade de cada um? Seu tempo? Seu meio?

Segundo Vieira e Freitas (2011), alguns princípios regem o processo, tais como: a promoção da atividade espontânea e natural dos sujeitos envolvidos e a verificaçáo das áreas de interesse (domínios das inteligências). As autoras destacam também que esta forma de identificação tem objetivos eminentemente educacionais e não clínicos "posto que as $\mathrm{AH} / \mathrm{SD}$ não devem ser entendidas como uma patologia e, sim, como um estado do desenvolvimento global do indivíduo" (VIEIRA e FREITAS, 2011, p. 66). Neste sentido, segundo Renzulli (2004), o processo de identificação deve ser de- 
finido por dois tipos de informação: a informação da situação e a informação da ação. O primeiro tipo de informação consiste em todo o conhecimento prévio sobre os potenciais apresentados pelos sujeitos; e a informação da ação diz respeito a todos os dados coletados/observados dos indivíduos em ação. Nesta proposta de intervenção, distribuiu-se os instrumentos padronizados e realizou-se a observação dos comportamentos dos sujeitos tanto nos grupos focais com a proposta de desafios, quanto nas entrevistas individuais para aprofundamento dos itens verificados.

\section{processo de identificação na prática...}

A metodologia utilizada nessa açáo esteve alicerçada no paradigma qualitativo, tendo como tendência metodológica o estudo de caso. A coleta dos dados para identificação dos sujeitos foi feita através das seguintes etapas: apresentação do projeto para o grupo e convite para participaçáo; aplicação de instrumentos padronizados, dentre eles a autoindicação e indicaçáo dos colegas; observação consistente e persistente dos fenômenos registrados durante a aplicação das atividades e discussóes de grupos focais, filmados em vídeo.

Como afirmam Vieira e Freitas (2011, p. 56), o processo de identificaçáo desde uma perspectiva qualitativa é "um processo contínuo, garantido pelo acompanhamento dos sujeitos ao longo do tempo e em diferentes situaçóes do seu cotidiano". Portanto, estas açóes não se esgotam nestas atividades, sendo necessário o acompanhamento dos acadêmicos ao logo do tempo para a verificação da intensidade, frequência e consistência dos indicadores percebidos durante o processo. As autoras definem estas categorias como:

A frequência diz respeito ao número de vezes que os comportamentos com indicadores de AH/SD aparecem no repertório da criança/jovem. Tal regularidade é importante, pois evidencia que não se trata de um "pico" no desenvolvimento do indivíduo, mas, sim, de atividades que ocorrem sistematicamente. A intensidade diz respeito à carga energética depositada na tarefa, demandando esforço contínuo e árduo. A consistência diz respeito ao resultado final da aprendizagem do aluno, implicando em um produto visível e valorizado pela sociedade em que o sujeito vive. (VIEIRA e FREITAS, 2011, p. 62)

Não tínhamos condiçôes de trabalhar com todos os alunos. Contatamos com a responsável por todos os grupos PETs, na Pró-Reitoria de Graduação (PROGRAD). Optou-se por trabalhar com os grupos vinculados à Secretaria de Educação Continuada, Alfabetização, Diversidade e Inclusão - SECADI. Após o estudo dos projetos de cada grupo PET, priorizamos dois grupos: o PET indígena e o PET educação no campo. Estabelecemos contato com a tutora do primeiro grupo, mas percebemos resistência por parte da mesma, justificando sua dificuldade em participar do projeto por excesso de atividade e por entender que o grupo indígena era muito visado na universidade e que esta ação poderia prejudicá-lo ainda mais. Apesar de ter gerado sentimento de frustração no momento da negação, hoje, após desenvolver o processo com dois dos quatro grupos, reconhecemos que nossa decisão de iniciar o processo 
de identificação pelo PET indígena foi prematura. Primeiro, porque não tínhamos vivência anterior no desenvolvimento deste processo com adultos; segundo, porque propor a identificação pela provisão para o grupo indígena implica em um aprofundamento maior nesta cultura, para definir e planejar corretamente quais são as propostas mais desafiantes para este grupo e quais são os indicadores mais confiáveis.

Assim, contatamos com o segundo e terceiro grupo. As tutoras prontamente consentiram em participar e agendaram reunião com todos os acadêmicos. Os grupos PETS participantes do estudo têm características especiais e por este motivo estão vinculados à Secretaria de Educaçáo Continuada, Alfabetização, Diversidade e Inclusão (SECADI). O Grupo A, vinculado à Educação Física, possui 12 alunos bolsistas oriundos da zona rural e atuando com diversos profissionais da área da saúde, fortalecendo e potencializando açóes de atenção primária a saúde e gerando espaços coletivos de discussão, pesquisa e capacitação pedagógica, junto às comunidades da zona rural. O Grupo B, vinculado às Ciências Sociais Aplicadas, possui 12 alunos de comunidades populares urbanas, oriundos de três cursos diferenciados numa abrangência multi/interdisciplinar. Porém 9 alunas participaram da atividade.

O trabalho foi desenvolvido no mesmo dia dos encontros do grupo e desenvolvíamos as atividades no tempo que nos era disponibilizado pelas tutoras. Portanto, nossos horários tinham que ser bastante flexíveis, pois os horários dos grupos variavam do horário do almoço ou no final de tarde. As atividades também tinham que se adequar ao tempo disponibilizado. Todas as reunióes foram filmadas e transcritas.

$\mathrm{Na}$ primeira reunião, apresentamos a proposta e o conceito de AH/SD trabalhado pela equipe para os dois grupos; foi distribuído o Termo de Consentimento para a participação e filmagem das atividades. Todos os participantes concordaram em participar da atividade e assinaram o termo de consentimento livre e assistido.

$\mathrm{Na}$ segunda, propomos grupos focais com os temas opção por estes PETs e vida escolar pregressa. E em continuidade foi proposta uma dinâmica vinculando seus nomes às características do grupo. Na terceira reunião alunos e tutoras receberam a Lista de Verificação de Identificação de Indicadores de AH/SD (FREITAS e PÉREZ, 2012). Na quarta reunião entregamos o Questionário para Identificaçáo de Indicadores de AH/SD em Adultos (FREITAS e PÉREZ, 2012) para preencher em casa e trazer na próxima reunião. Tal procedimento tinha a intenção de verificar o comprometimento com a tarefa destes acadêmicos. Todos trouxeram a ficha preenchida, menos duas alunas que faltaram aos encontros.

Cabe destacar dois aspectos relacionados à identificação pela provisão proposta para os acadêmicos: a organização das atividades de dinâmica de grupo, com exceção da dinâmica dos nomes, não foram as mesmas para os dois grupos, concentrando-se o foco do Grupo A nas atividades corporais, liderança e criatividade e, no Grupo B, atividades linguísticas, produção de texto, liderança e criatividade. Em segundo lugar, houve aceitação e engajamento de todos os dois grupos na execuçáo das atividades, apesar do respeito à liberação de quem não quisesse participar da atividade. 
O processo de identificação obteve os seguintes resultados: no Grupo A foram identificados quatro (4) alunos sendo duas (2) mulheres e dois (2) homens, todos solteiros, do interior do estado do RS, nenhum filho único e com média de idade entre 20 e 22 anos. No Grupo B também obtivemos quatro (4) acadêmicas, sendo todas do sexo feminino, solteiras, do interior dos estados do Rio Grande do Sul (RS) e Santa Catarina (SC), nenhuma filha única e com média de idade entre 19 e 21 anos. A segunda etapa do processo está em andamento, com os objetivos de aprofundar o conhecimento sobre os acadêmicos, acompanhar o desenvolvimento dos indicadores e, também, propiciar o conhecimento entre si.

Cabe destacar que, por problemas de saúde, a tutora do grupo B esteve afastada durante o período do processo de identificação, não tendo, portanto, participado do mesmo. No entanto, no momento em que a responsável retornar, será solicitada sua colaboração.

\title{
Alguns resultados obtidos...
}

O desenvolvimento destes encontros com os dois grupos PET selecionados possibilitou conhecer a vida acadêmica desses alunos, bem como, os projetos desenvolvidos pelos mesmos. Ao mesmo tempo, nos permitiu entender melhor como estes alunos são percebidos pelos demais colegas e professores. O próprio fato de pertencer ao PET faz com que estes acadêmicos sejam percebidos de forma diferenciada pelos colegas e professores e, em muitas vezes, ser alvo de gozação, tal como o depoimento abaixo:

\begin{abstract}
Quando eu entrei no projeto no grupo mesmo eu senti bastante gozaçáo dos meus colegas, davam risadas,- então entrou no grupo PET-, qualquer coisa que eu fazia até a primeira vez que usei a camiseta do PET eles me tiraram a (nome da aluna) não toma mais refrigerante de latinha agora só de Pet... tipo aquelas piadinhas sabe (risos) é, eu senti bastante isso porque eu fui a única da minha turma a procurar este lado. (C., Sexo F., 20 anos)
\end{abstract}

Um aspecto importante para todos os sujeitos identificados foi a entrada na faculdade. Exemplo desta afirmação são os depoimentos de dois dos alunos: "Na universidade foi um marco na minha vida. Totalmente... quebrou, é M. J. antes e M. J. depois. (...)" (M.J. Sexo F., 20 anos) e "Ah eu acho que a mais prazerosa foi quando eu passei no vestibular" (G. Sexo M., 22 anos). Da mesma forma, a participação no PET permite que desenvolvam projetos vinculados a suas áreas de estudo e interesse, apesar de um dos participantes abordar uma crítica relevante relacionada ao trabalho:

Eu acho que agora também é um momento difícil porque a gente não conseguiu ainda emplacar o nosso trabalho.. (...) é uma coisa muito nova esse trabalho com a população rural e também inserir a educação física dentro da área da saúde.. Trabalhar com essa saúde mais clinica.. é um desafio grande, eu acho. (G. Sexo M., 22 anos)

É possível observar-se com clareza sua preocupação e autocrítica e a atração para o desafio. Apesar destes sentimentos, o acadêmico não desiste. 
Sobre o atendimento às pessoas com AH/SD na universidade é possível afirmar que todos desconheciam o assunto e a primeira atitude que tomariam, se tivessem oportunidade de implantar um atendimento, seria a de aprofundar o estudo sobre a área e "depois conhecer a pessoa e através dela e de repente ver alguma forma de poder ajudá-la seja dentro do serviço, dentro da escola". (L., Sexo F., 22 anos). Todos destacaram a importância de informar à pessoa sobre suas características especiais.

Em relação à presença dos indicadores de AH/SD foi possível perceber que as alunas sentiram-se surpresas com o resultado, porém os dois alunos já o esperavam. Também, foi salientado que as famílias percebiam seus comportamentos diferenciados, porém não entendiam como manifestaçóes de AH/SD. Somente depois do processo de identificação estas situaçóes adquiriram sentido para eles.

Eu não esperava o resultado. Eu... sei lá... tipo... eu me via como um integrante normal... assim. Eu sempre... eu tenho... eu tinha esta característica, estou percebendo muito mais agora (...) eu percebi mais na faculdade, quando eu entrei que eu era mais líder da turma. (M.J., sexo F., 20 anos)

Foi bem tranquilo pra mim, assim. Na verdade eu não tinha muita expectativa, assim, sabe... pra mim era uma coisa normal. Eu náo esperava muita coisa. Eu já sabia um pouco assim (das características apontadas), teve um indicativo forte de... de... bah agora esqueci o nome... de... perfeccionismo. (...) Às vezes eu me sinto um pouco diferente assim, mas nunca me passou pela cabeça que poderia ser alguma habilidade. (G., sexo M, 22 anos)

A dificuldade que as pessoas do sexo feminino demonstram em perceber-se com comportamentos indicadores de AH/SD é bastante comum. A característica dos participantes do Grupo A é ser oriunda de municípios do interior do estado e, quase todos pertencentes a famílias que subsistem do meio agropecuário. Assim, ainda é comum, nesta cultura, a mulher ser preparada para as atividades domésticas e o homem para o provento da casa e da família. Neste sentido, há uma valorização das atividades masculinas em detrimento das femininas, o que explica esta situação de desvalorização dos potenciais femininos.

Chama atenção, também, a sensação de estranhamento causada pela identificação destas características com a verbalização de não ser "normal". Esta é uma das características que faz com que o adulto com $\mathrm{AH} / \mathrm{SD}$ mascare seus potenciais para não parecer diferente do grupo. Outro ponto que chama atenção é a questão da criatividade, somente um dos participantes se reconhece como criativo. Apesar da negação da presença dos indicadores de AH/SD por parte da maioria dos participantes, encontramos: perfeccionismo, curiosidade, criatividade, liderança, persistência, senso de humor, autonomia, preferência por desafios, liderança, autonomia. Como é possível observar muitos destes indicadores são citados por Pérez (2008) e Delpretto (2009) como comuns em pessoas com AH/SD adultas. 
Em relação à proposta de identificação pela provisão foi possível observar algumas características já encontradas, quando do trabalho com crianças pequenas (VIEIRA, 2005a). O primeiro fator é a possibilidade de articular e modificar as técnicas de coletas das informaçôes considerando as características do grupo a ser identificado, do tempo e espaço físico disponibilizado para o processo. Proporcionando, portanto a adequação das açóes, de tal forma que os objetivos propostos pudessem ser atingidos.

Os fatores afetivos são importantes neste processo, tanto para quem está na função de articulação e coordenação das atividades, quanto para aqueles que estão participando. Assim sendo, o clima de satisfação, abertura, cordialidade, respeito, informalidade persistiu durante todas as intervençôes e favoreceram para que os acadêmicos pudessem mostrar-se de forma espontânea. Ao mesmo tempo foi possível observar que todos os alunos que participam destes dois grupos PETs estão satisfeitos com sua escolha profissional e com sua ação como profissionais nas comunidades, são alegres, curiosos e participativos, o que desperta em quem entra um grande desejo de trabalhar com/neste estes grupos.

O terceiro aspecto está relacionado ao que Ramos-Ford e Gardner (1991) caracterizaram como perspectiva ecológica, pois, ao experimentarem situaçóes vinculadas ao seu dia-a-dia e com materiais (re)conhecidos, os acadêmicos tiveram oportunidade de demonstrar sua compreensão nas diferentes questóes surgidas da interação com os colegas e com as atividades propostas, possibilitando o exercício de diferentes respostas a estas situaçóes.

\section{Para finalizar a discussão...}

Como já referimos, embora se fale em múltiplos instrumentos, tradicionalmente, os resultados obtidos nos testes de inteligência são decisivos para a identificação de quem apresenta AH/SD. Muitas são as dúvidas em um trabalho que pretende utilizar outros procedimentos que não os estandartizados. Assim cabe perguntar: a identificação pelos indicadores numa perspectiva qualitativa pode ser confiável? Propor uma intervençáo desde a abordagem qualitativa gera muita insegurança. Mas, ao mesmo tempo, transforma-se em um espaço de criação e flexibilização importantes objetivando a adequaçáo dos procedimentos de acordo com o grupo a ser identificado.

Optamos, neste trabalho, em utilizar uma abordagem diferente que já está consolidada com crianças e adolescente, mas que ainda tem poucos estudos com adultos. Mas, que pelas experiências vivenciadas neste estudo permitiram concluir que a identificação pela provisão é possível de realizar também com adultos. As vivências de dinâmica facilitaram o reconhecimento dos indicadores de AH/SD nos acadêmicos, além de se constituírem em uma experiência prazerosa para todos os envolvidos.

As dificuldades encontradas foram as barreiras atitudinais e a pouca bibliografia na área. $\mathrm{Na}$ literatur,a há diversas crenças errôneas sobre estes sujeitos e nesta atividade de pesquisa encontramos duas: a que o sujeito com AH/SD não deve saber 
que tem este potencial e o medo de que esta informação possa trazer de malefícios ao sujeito.

O processo de identificação deverá continuar tanto com estes e, quanto com os outros acadêmicos dos grupos PETs ainda náo contados. No entanto, cabe destacar que náo foi encontrada necessidade de intervenção com estes dois grupos, pois suas necessidades estão supridas pelo programa, o que reforça nossa ideia inicial de que o PET é uma boa proposta de atendimento aos alunos com AH/SD na universidade. Portanto, o PET é um recurso importante para a inclusão destes acadêmicos que, pelo apoio dos colegas e da tutora, se sentem reconhecidos e fortificados em sua autoestima.

\section{Referências}

BRASIL. Presidência da República. Casa Civil. Subchefia de Assuntos Jurídicos. Lei 11.180 de 23 de setembro de 2005. Institui o Programa de Educaçăo Tutorial - PET p altera a Lei 5537de 21 de novembro de 1968 e a CLT aprovada pelo Decreto-Lei 5452 e dá outras providências. Disponível em: <http://www010.dataprev.gov. br/sislex/paginas/42/2005/11180.htm>. Acesso em: 08 abr. 2012.

Programa de Educação Tutorial. Manual de Orientaçóes. Brasília: MEC, 2006. Disponível em: $<$ http://portal.mec.gov.br/index.php?option=com_content\&view=article\&id=12228\%3Aprograma-de-educacao-tutorial-pet\&catid=232\%3Apet-programa-de-educacao-tutorial\&Itemid=480>. Acesso em: 09 abr. 2012.

DELPRETTO, B. Pessoas com altas habilidades/superdotação adultas: lembranças do processo de escolarização. Revista Contrapontos, (Eletrônica), v. 10, n. 2, p. 218-235, maio/ago. 2010.

A pessoa com altas habilidades/superdotaçáo adulta: análises do processo de escolarizaçáo com elementos da contemporaneidade. Dissertaçáo (Mestrado) Universidade Federal de Santa Maria, Centro de Educação, Programa de Pós-Graduação em Educação. Santa Maria, 2009.

FREEMAN, J.; GUENTHER, Z. C. Educando os mais capazes: idéias e ações comprovadas. São Paulo: EPU, 2000.

FREITAS, S. N.; PÉREZ, S. G. B. Altas Habilidades/superdotaçáo: atendimento educacional especializado. Marília: ABPEE, 2010.

Altas Habilidades/superdotação: atendimento educacional especializado. Marília: ABPEE, 2012. 2º edição revista e ampliada.

GARDNER, H. Inteligência: um conceito reformulado. Rio de Janeiro: Objetiva, 2000.

GARDNER, H.; FELDMAN, D. H. ; KRECHEVSKI, M. Projeto Spectrum: a Teoria das Inteligências Múltiplas na Educação Infantil - Utilizando as competências das crianças; V.1. Porto Alegre: Artmed, 2001.

MEIRIEU, P. Aprender... sim, mas como? Porto Alegre: Artemed, 1998.

MOSQUERA, J. J. M.; STOBÄUS, C. D.; FREITAS, S. N. Altas Habilidades/Superdotação: abordagem ao longo da vida. Revista Educaçáo Especial. v. 26, n. 46, p. 401-420, maio/ago, 2013.

PÉREZ, S. G. P. B. Ser ou náo ser, eis a questáo: o processo de construção da identidade na pessoa com altas habilidades/superdotação adulta. Tese de Doutorado: Porto Alegre, 2008.

PLUCKER, J. Intelligence theories on gifted education. Roeper Review, Bloomfield Hills, MI, v. 22, n. 3, p. 124-125, 2001

RAMOS-FORD, V.; GARDNER, H. Giftedness from a Multiple Intelligence perspective. In: COLANGELO, N ; DAVIS, G. A. Handbook of a gifted education. Boston: Allyn \& Bacon, 1991, p. 55-64.

RENZULLI, J. O que é esta coisa chamada superdotação e como a desenvolvemos? Uma retrospectiva de vinte e cinco anos. Educaçáo, Porto Alegre, RS, n.1(52), 2004, p. 75-131.

. Enriching Curriculum for all studentes. Illinois: SkyLight, 2001

The three-ring conception of giftedness: a developmental model for creative productivity. In: REN-

ZULLI, J. S. ; REIS, S. The triad reader. Connecticut: Creative Learning Press, 1986. 
VIEIRA, N. J. W. "Viagem a Mojáve-Óki”! Uma trajetória na Identificaçâo das altas habilidades/superdotação em crianças de quatro a seis anos. Tese (Doutorado). Faculdade de Educação. Programa de Pós-graduação em Educaçáo. Universidade Federal do Rio Grande do Sul. Porto Alegre, 2005a.

. Inteligências múltiplas e altas habilidades: uma proposta integradora para a identificação da superdotação. Revista Linhas, v. 6, n. 2, 2005b. Disponível on-line em: <http://www.periodicos.udesc.br/index.php/ linhas/article/view/1270>. Acesso em: 11 abr. 2012.

Identificaçáo das altas habilidades em crianças de três a seis anos: a busca de uma proposta integradora. Projeto de Tese (Doutorado em Educação), Programa de Pós-Graduação da Faculdade de Educaçấo, Universidade Federal do Rio Grande do Sul, Porto Alegre, 2002.

VIEIRA, N. J. W.; FREITAS, S. N. Procedimentos qualitativos na identificaçáo das altas habilidades/superdotaçăo. In: BRANCHER, V. R.; FREITAS, S. N. (Org.).Altas Habilidades/Superdotação: conversas e ensaios acadêmicos. Jundiaí/SP: Paco, 2011.

\section{Notas}

${ }^{1}$ Dados fornecidos pelo Núcleo de Acessibilidade baseados nos dados emitidos pelo Departamento de Registro Acadêmico - DERCA em novembro de 2013.

${ }^{2}$ Segundo Portal da UFSM (http://portal.ufsm.br/indicadores/select/1). Acesso em 13/05/2014.

${ }^{3}$ Neste momento, utilizamos o termo "superdotado" para nomear um tipo específico de sujeitos que se destacam nas atividades acadêmicas e, que são denominados, segundo Renzulli (1986), de superdotado acadêmico, pois é muito comum reconhecermos estes sujeitos como superdotados e aqueles que se destacam nas áreas artísticas como "talentosos".

${ }^{4}$ Entendemos a definição de indicadores de acordo com a concepção adotada por Meirieu (1998, p.187): todo o "comportamento observável a partir do qual se pode inferir o alcance de um objetivo ou o domínio de uma capacidade".

\section{Correspondência}

Nara Joyce Wellausen Vieira - Universidade Federal de Santa Maria, Centro de Educação - Departamento de Educação Especial. Av. Roraima, 1000. Cidade Universitária, Camobi, CEP: 97105900 - Santa Maria, Rio Grande do Sul - Brasil.

E-mail: najoivi@gmail.com

Recebido em 05 de abril de 2014

Aprovado em 11 de junho de 2014 
